\title{
LETTER
}

\section{Re-thinking resuscitation goals: an alternative point of view!}

\author{
Paul E Marik ${ }^{* 1}$ and Rinaldo Bellomo² \\ See related viewpoint by Dünser et al., http://ccforum.com/content/17/5/326
}

We respectfully disagree with several key assertions made by Dünser and colleagues [1] in this issue of Critical Care and consider their approach to resuscitation to be potentially harmful. Septic shock is not primarily a volume-depleted state, and attempts to treat vasoplegic shock with fluids alone will compound the macro- and micro-circulatory abnormalities of sepsis. A vasopressor with both $\alpha 1$ and $\beta 1$ adrenergic activity (norepinephrine) will increase arterial tone, preload, and cardiac contractility [2]. Early administration of norepinephrine is associated with improved hemodynamics and reduced mortality in patients with sepsis [2,3]. Permissive hypotension is an untested and potentially dangerous concept. When the mean arterial pressure (MAP) falls below an organ's autoregulatory threshold, organ blood flow decreases in an almost linear fashion [4]. Because the autoregulatory ranges of the heart, brain, and kidney are above $45 \mathrm{~mm} \mathrm{Hg}$ [4], such a blood pressure will, as one would expect, predictably decrease organ blood flow. Lehman and colleagues [5] have convincingly demonstrated that the risk of kidney injury and death increases sharply with an MAP of below $60 \mathrm{~mm} \mathrm{Hg}$. The notion that sepsis is associated with tissue hypoxia is unproven and, as Hotchkiss and Karl [6] argued over 20 years ago, is likely to be incorrect. Attempts to titrate therapy to a nonexistent oxygen debt on the basis of an elevated lactate concentration are doomed to fail. Similarly, the use of central venous oxygen saturation to guide the resuscitation of patients with sepsis is problematic. Although urine output may be a valuable marker of renal perfusion in hypovolemic states, this clinical sign becomes unreliable in sepsis-associated acute kidney injury, in which experimental models show that oliguria occurs in the presence of marked global renal hyperemia

*Correspondence: marikpe@evms.edu

'Division of Pulmonary and Critical Care Medicine, Eastern Virginia Medical School, 825 Fairfax Avenue, Suite 410, Norfolk, VA 23507, USA

Full list of author information is available at the end of the article
[7]. In summary, we consider that the first step in the resuscitation of patients with septic shock is to achieve an MAP of at least 60 to $65 \mathrm{~mm} \mathrm{Hg}$ with the use of vasoactive agents (norepinephrine) and small volumes of balanced fluid. A simultaneous goal would be to ensure adequate flow (cardiac output) as determined by echocardiography and minimally invasive cardiac output monitoring and supported by an integrated assessment that includes monitoring the patient's clinical response to therapy.

\section{Abbreviation}

MAP, mean arterial pressure.

\section{Competing interests}

The authors declare that they have no competing interests.

\section{Author details}

'Division of Pulmonary and Critical Care Medicine, Eastern Virginia Medical School, 825 Fairfax Avenue, Suite 410, Norfolk, VA 23507, USA. ²Department of Intensive Care, Austin Hospital, Heidelberg, Melbourne, Victoria, 3084 Australia.

Published: 8 October 2013

\section{References}

1. Dünser MW, Takala J, Brunauer A, Bakker J: Re-thinking resuscitation: leaving blood pressure cosmetics behind and moving forward to permissive hypotension and a tissue perfusion-based approach. Crit Care 2013, 17:326.

2. Hamzaoui O, Georger JF, Monnet X, Ksouri H, Maizel J, Richard C, Teboul JL: Early administration of norepinephrine increases cardiac preload and cardiac output in septic patients with life-threatening hypotension. Crit Care 2010, 14:R142.

3. Abid O, Akca S, Haji-Michael P, Vincent JL: Strong vasopressor support may be futile in the intensive care unit patient with multiple organ failure. Crit Care Med 2000, 28:947-949.

4. Bellomo R, Di Giantomasso D: Noradrenaline and the kidney: friends or foes? Crit Care 2001, 5:294-298.

5. Lehman LW, Saeed M, Talmor D, Mark R, Malhotra A: Methods of blood pressure measurement in the ICU. Crit Care Med 2013, 41:34-40.

6. Hotchkiss RS, Karl IE: Reevaluation of the role of cellular hypoxia and bioenergetics failure in sepsis. JAMA 1992, 267:1503-1510.

7. Wan L, Bagshaw SM, Langenberg C, Saotome T, May C, Bellomo R: Pathophysiology of septic acute kidney injury: what do we really know? Crit Care Med 2008, 36:S198-S203.

doi:10.1186/cc12775

Cite this article as: Marik PE, Bellomo R: Re-thinking resuscitation goals: an alternative point of view! Critical Care 2013, 17:458. 